\title{
Deep-Sea Fisheries: The Lessons of Experience
}

\author{
Cath Wallace and Barry Weeber
}

\section{Background}

This article draws on a comprehensive research paper "Between the D evil and the D eep Blue Sea" which we presented to the D eep Sea 2003 Conference in Q ueenstown. In that paper we set out to examine the N ew Zealand Fisheries Q uota M anagement System (Q M S) and its issue of property rights to commercial fishers in the deep-water fisheries within adjustable catch limits.

In the following pages, we argue that one should focus on thequestion; have property rights provided sufficient incentive to protect the resource and the host environment? If not, what adjustments might need to be made in the mechanisms through which the Q M S was applied? Of these, the central features have been the Individual Transferable Q uota (ITQ ) and the setting of catch limits.

The central policy challenge is to understand the performance of the quota system and to consider it as an example of a market-based instrument which had been designed to reset incentives through a property rights mechanism. The evaluation then leads to identifying lessons to be learned. For example, we state below the need to focus on the precise nature of the "property" which this particular instrument assigns to the transferee.

Property rights issues have been advanced in the theoretical literature as a market-based mechanism through which over-fishing may be controlled in precisely thismanner. As a lead nation in theexperiment with ITQ s, the N ew Zealand experience is important.

The case history of orange roughy is based on official figures and has been developed from the $Q$ ueenstown presentation. As in other jurisdictions, the decline in stocks of this species has been very dramatic. In $\mathrm{New}$ Zealand, the failure of the ITQ device has led to some belated closures of fishing areas to all ow recovery to take place - and arguably more are required. There is a significant international body of opinion that extensive marine reserves are needed as an "insurance" against fishery management failures. That discussion needs to be had, but we do not cover it here.

\section{The switch to management by quota}

It is now morethan 20 years sincea quota management system was introduced in order to control the harvest from $N$ ew Zeal and's deep-sea fisheries. This happened just five years after the declaration in 1978 of an Exclusive Economic Zone (EEZ) around $\mathrm{New}$ Zealand. This stretches from 12 to 200 nautical miles $(\mathrm{nm})$ out from the territorial coastline (including offshore islands). Such a step was sanctioned by the negotiations leading up to the U nited Nation's Convention on the Law of the Sea (1982) and it brought about a dramatic expansion of the sea area and fisheries under this country's control.

At the time, an ineffective access regime had been in operation in theinshorefisheries. Therewas little doubt that it would have to be replaced by a better system. In some fisheries effective open access existed and it was well known that fisheries exposed to open-access extraction tend to be harvested at high levels and to become depleted far below the economic optimum. Attempts to control fishing effort were based on restrictions on the types of fishing gear, periods during which fishing was permitted, and the precise specification of equipment to be used, such as mesh size. Such restrictions, valid for biological protection, were also used, inefficiently, to control the amount of fishing effort. This led to higher costs than necessary, especially when compared to methods which set limits to the total harvest from a fishery. 
Internationally, this dual problem of inefficiency and overharvesting had become the subject of attention by economists to see if reliance on harvest limits, coupled with market-based instruments in the form of property rights to access the fishery, might provide an incentive for efficiencies and better biological outcomes. The quantity limit was seen as allowing fishers to achieve this by choosing their own methods, whilestill reducing overfishing. The property right is no more than a right to access the fishery to take a given quantity or share of the total allowablecatch. Theproperty rightsin $\mathrm{N}$ ew Zealand waters were expressed within a system of "individual transferablequotas" (ITQ s). Thesewereseen as providing fishers with an incentiveto protect the value of their asset - they would enjoy the right to access the fishery (but not possession of the fish stock itself).

Ahead of most other jurisdictions, $\mathrm{N}$ ew Zealand placed its quota management system under an overall constraint on annual harvest (the "total allowable catch" or TAC) and proclaimed that this would becapped at a sustainable level. ThisTAC would then beshared among commercial, recreational, customary and science harvesters. O nly commercial fishers were issued with quota, initially as a set quantity. N ow this is allocated as a proportion of the commercial share, defined as the Total Allowable Commercial $C$ atch (TACC). These limits are issued for each species, or species group, in defined zones known as "quota management areas" (Q M As). O ther fishers, not within the ITQ system, aregoverned by other rules.

In the deep-water fisheries, $\mathrm{N}$ ew Z ealand introduced a Q uota M anagement System with a trial in 1983. The system was formal ised and extended to inshore species in 1986, so we now have considerable experience with these market-based instruments. The security of the share of the fishery offered to commercial fishers by their individual quota was expected to remove the "race to fish" and to provide an incentive for fishers to protect the stocks, given that their quota values depend on sustainable stocks. This "race" occurs when fishers stuff their vessel with catching technology and proceed to over-fish, leading to biological losses and economic inefficiency.

Commercial fish quota owners have the ability to form a "club" of fishing quota owners. Thetheory wasthat such a collective would then form mutually enforceable rules. They would decide how much effort to put into selfpolicing. In fact, the major burden of compliance and enforcement has relied on efforts by government agencies responsible for fisheries control and scientific research.

There are some key lessons to be drawn from $\mathrm{N}$ ew Zealand's deep-water fisheries experience. With the benefit of hindsight, it is now possible to use stock assessment reports over a twenty-year period and attempt to answer some of the key policy questions. The record of theorange roughy fisheries providea mixed but clearly discouraging picture, with assessed stocks ranging from $3 \%$ to an upper bound estimate of $54 \%$ of the original biomass for different stocks, on 2003 figures (see detail on pp14-15). O utcomes for other stocks in the deepwater, such as the oreo species, reveal significant and risky declines.

Appropriatetechniquesfor environmental management were given little real attention from the outset. Protective measures, where they have been introduced at all, have been slow, piecemeal and reactive, rather than proactive. Nineteen seamounts were eventually closed to fishing in 2001, but there has been, over the 21 year period considered, no formalised and comprehensive standard environmental assessment process, and until April 2005 it appeared that any overall strategy for assessing the impacts of fishing was to be shelved in favour of single-stock management.

\section{Harvesting theory, valuation, and property rights as a protective mechanism}

Since the nation's fisheries represent both market and non-market values, it follows that the harvesting of marketable fish species will generate a range of external costs (which will not be reflected in market prices). Bycatch is a very clear illustration. This results in the discarding of non-targeted non-quota species and, in some instances, a reduction in biodiversity (where fishing impacts on other species and communities). Similarly, when an operation such as bottom trawling crushes colonial corals and other benthic habitat, there will be costs external to any market transaction (comparable to some extent with the effects of clear cutting a native forest).

Economists use the concept of "Total E conomic Value" to reflect the fact that the value of fish sold on the market is only one small part of the value that people attach to fish. N on-market economic values can include: 
- the values attached to retaining an intact marine environment (including thestock of fish) for its own sake (existence value);

- the values of ecosystem functions and the services that these represent (in this case for instance, habitat, predator-prey relationships);

- the values of non-extractive uses (such as observation or scientific enquiry);

- the recreational and aesthetic values we attach to the marine environment and fisheries;

- the value society places on handing the resource on to future generations in good shape (bequest value);

- the value put on retaining options for all uses and benefits in future (option value).

In public policy terms, this particular mix means that market values cannot be the sole criterion for fisheries management. Economic efficiency requires that the sources of benefit in the bullet points above be made part of the efficiency equation. When all the instrumental values incorporated in "Total Economic Value" are considered, it is unlikely that optimisation of commercial market values will coincide with economic efficiency.

Core harvesting theory, on the other hand, considers only harvest values. It suggests that a single owner wanting to maximise market harvest values for a stock should optimisethelevel of fishing effort and fish stocks remaining by considering:

- the physical productivity of the fish stock;

- the impact on future productivity by current harvesting;

- changes in costs as a result of harvesting and other elements;

- future expected revenues, and

- the discount rate (reflecting preference for returns now rather than in thefutureand alternativeoptions for investment).

Thesetting of catch limits (combined with the allocation of a property right) was designed to prevent the "race to fish" syndromedescribed above. TheTAC may however be adjusted from year to year so commercial operators lack one important element of security - exactly how big is next year's permitted catch? Faced with uncertainty, they will have a strong incentiveto maximize catch since any conservation gains are lost to future harvests.

We can see therefore that if the design of the quota mechanism is determined purely by market values, it is highly probablethat long-lived, slow-growing fish stocks will be "mined" and the proceeds deployed to higher yielding investments. This arises because the returns available elsewheregrow faster than the net capital value of the slow-growing stock. The higher the discount rate, or preference for returns now, the more likely it is to lead to higher levels of fishing and lower fish stocks.

The proceeds from the sale of the fish stock can then be expected to grow faster than the net capital value of the fish remaining in the sea. It is for this reason that the allocation of property rights will not automatically create sufficient incentives for quota owners to ensure that the target stock is maintained.

\section{New Zealand's quota management system - the practice}

At the core of the new system when it was introduced in 1983 (for deep-water fishing, in depths greater than $700 \mathrm{~m}$ ) was the allocation of property rights through the ITQ . For a given species or species group, quotas would be calculated on the basis of total allowable catch in a given area. It was expected that the mechanism would improve efficiency in the industry, while still ensuring that the harvest was held within "maximum sustainable yield". The latter concept is a single-stock biological harvest concept, not an economic or ecological term, and requires good science (constantly updated) on the population dynamics of the species in question.

The reasoning behind the shift to quantity limits, and away from controls over the type of gear used or the periods/seasons when fishing would be allowed, was sound enough. It was expected to induce higher efficiency in fishing operations overall and to eliminate the pressures which generate "race to fish" behaviour. Similarly, it was reasonable to promote (as one element in the policy) the formation of quota owner associations in order to improve compliance - the expectation being that they would apply their own rules to diminish competitive fishing and cheating.

We have seen, however, that the core incentive to mine fish stocks as described above was not removed. The non-harvest values of fish havenever been considered by 
the M inistry of Fisheries because of its interpretation of the term "utilisation" in 5.8 , which sets out the purpose of the Fisheries Act 1996. "Utilisation" is defined there as meaning "conserving, using, enhancing, and developing fisheries resources to enable people to provide for their social, economic and cultural wellbeing". The M inistry, however, maintains that it actually refers solely to use for harvesting (M inistry of Fisheries, "Section 8 Policy D efinitions", p8 c2002). We disagree, on the grounds that there is nothing in the definition of "utilisation" to restrict the meaning to extractive uses only, and indeed, there is much to suggest otherwise.

There was another missing element in the policy design. It arises from the pervasive incentive to externalise both the effects on the environment and the costs of lost nonextractive values. In deepwater fisheries, there are numerousslow-growing species with no market value(this istrueboth of fish and of the colonial animalsthat provide important habitat structures). There has to beavery rapid change in harvest levels for any market mechanism to recognize an incentive to protect the environment.

Set out overleaf is thepopulation history of orangeroughy, using the officially accepted figures, where catch declined very steeply in almost every area of the fishery following theimposition of thequota system in deepwater fisheries in 1983. Similar trends have been recorded for most of theother deep-water species which comeunder the quota management schemeand for the "mid-water" hoki fishery, originally a huge stock that has suffered marked decline. The $\mathrm{N}$ ew Zealand experience in this respect is of international interest, given theclaimsthat wereoriginally made, and continue to be advanced, for the success of the quota management system.

\section{Institutional and process failure?}

Reviewing the twenty-year period of ITQ operation in $N$ ew Zealand, oneisstruck by theinstitutional evolution and the "work-in-progress" character of themechanism. Public policy was administered under intense industry pressure and on the basis of unduly optimistic assumptions about incentives, stocks and outcomes. The precautionary approach to resource management is not often in evidence. There is an assumption of greater importance of commercial interests over any other, both by industry and by many (but not all) officials and M inisters, partly dueto the industry'sability to mount legal challenges. There has been a reluctance (especially by the industry) to have adequate resources put into independent scientific environmental appraisal. We consider that a dismissive attitude on the part of many officials towards the environmental and futureregarding provisions in the Fisheries Act (1996) was evidenced by their dubbing these "the religious bits", a term used frequently at meetings.

Industry players and administering officials in almost all other environmental and resource management sectors have to face regular public input into management plans, policies and the like, frequently under statutory process. Fisheries management in $\mathrm{N}$ ew Zealand has, by contrast, lacked regular public process and engagement has been limited to "approved parties"1.

Fisheries $\mathrm{M}$ anagement Plans were abolished in the mid 1990s. The perception of officials at the time was that they were cumbersome. Barebones legislative authority for new forms of fisheries plans was introduced by the FisheriesAmendment Act 1999. The M inistry produced 3 initial papers on these plans in M arch 2001. Subsequent work, including consultation, has resulted in their elaboration. Significantly, the M inistry of Fisheries has proposed that harvesters hold the pen and that other interests be asked to make submissions to them. The M inister would then approve or decline the resulting fishery plans but would not be allowed to change them. This proposal is apparently based on the argument that industry compliance will depend on their agreement with the plan. This subjugation of nonharvesters, non-quota owners, and the M inister of Conservation to plans defined by quota owners has been the source of great contention.

\section{A forward agenda}

Any attempt to improve future decision-making in this sector, while retaining quantity limits, with IT Q sas the key tool for management of the resource, would have to tackle the following agenda:

\section{- Where does environmental science feed into the process?}

Stock assessment will always be an inexact science, but ecosystem assessment is even harder. Stock

1 "Approved Parties" are the nationally organized representatives of commercial, recreational and customary fishers, environmental interests and occasionally others, who apply to an gain approval annually from the Minister to be consulted under s.12 of the Fisheries Act 1996. 


\section{Decline and Closure in the}

The story of the orange roughy fishery is instructive, since it has been the dominant deep-water species over 20+ years of management under ITQs, both in terms of volume and in terms of price and value. Annual catches of 40-50,000 tonnes were recorded during the 1980 s, peaking in $1989 / 90$. Since then there have been significant catch reductions leading to progressive (but lagged) reductions in catch limits for individual fisheries. The consequence of this has been a drop in the quantity allocated under ITQs, since these are expressed as a percentage of the total allowable catch. In the deepwater, there is no recreational or customary catch, so these reductions are not due to non-commercial fishing.

For all fish stocks "- with the controversial exception of bycatch stocks - there is a legal requirement for the Minister to ensure that fish stocks are maintained "at or above" the level that will produce the maximum sustainable yield (Fisheries Act 1996, s13). For orange roughy, this minimum stock size has been set at $30 \%$ of the original unfished biomass. At that level, it is estimated that the stock will provide a "maximum sustainable yield" in terms of biological replacement for the extracted harvest.

The overall decline in orange roughy stocks is brought out more starkly when the stock assessments are traced for each of the quota management areas for this species see graphs opposite for the period 1983 to 2003. These are the officially accepted stock assessments, and they demonstrate a pattern of separate and significant declines. In two-thirds of the cases, stocks have fallen well below the $30 \%$ mark, some to as low as 3\% and 7\%: (yet in 2005 the fishing industry wants to reopen one of these, without any indication that the stock has recovered).

Fishing was allowed to continue for many years as the stocks declined further, though the Ministry of Fisheries claims that these are on a path to recovery. Despite these claims, with the exception of the Chatham Rise fisheries, there is little evidence of stock rebuilding. Environmental organisations have lacked resources to take legal action against what they saw as disregard for the requirements of s.13 of the Act.

The Ministers in office during the period have mostly erred on the side of generosity to the fishing industry, usually pitching catch limits above those recommended by scientists and environmentalists, often at or above the level suggested by the fisheries management officials - bringing most of their decisions close to what the industry wanted. Catch limits have been reduced but usually by a significant lag behind the stock assessments.

The Challenger and Puysegur fisheries were only closed when they reached $3 \%$ and $7 \%$ of the original biomass respectively. Environmental organisations attempted to get science done on the impacts of bottom trawling. In the late 1990s and early 2000s, research was commissioned from NIWA on this aspect. Results to date show significant damage done by trawling.

When Pete Hodgson took the reins as Minister in 1999, he reversed years of inaction and agreed to the closure of 19 seamounts in 2001 , some already fished, some too deep to fish, and some potentially fishable.

The overall picture which emerges from the orange roughy experience leads on to a series of questions, not only concerning the ITQ as an appropriate device for sustainable management in deepwater fisheries, but also about the decision-making processes, the inputs into those processes and the institutional framework within which they occur.

\section{SUMMARY OF TOTAL CATCH}

\begin{tabular}{|lc|}
\hline Year & Recorded catch (tonnes) \\
\hline $1982 / 83$ & 48,207 \\
$1986 / 87$ & 52,332 \\
$1991 / 92$ & 37,013 \\
$1996 / 97$ & 16,645 \\
$2001 / 02$ & 14,381 \\
\hline
\end{tabular}

assessment is an important component, but only one part of the necessary science. When stock and environmental estimates have a widemargin of error, then catch limits and catch method controls must be precautionary.

\section{- Who commissions and does the science, and who owns the data?}

There is a clear danger in implying that theindustry has an untrammelled property right over the deepwater resource - other than a permit in perpetuity to harvest a share of the allowable commercial catch subject to environmental protection and other social goals for the fishery. The Fisheries Act makes it clear that sustainability must be ensured and that future generations' needsmust be provided for (s.8). Industry entitlements are subject to obligations and to wider social goals. Industry ownership (or control) over the commissioning, contracting, or performing elements of the scientific process was enabled in the Fisheries Amendment Act 1999 over the objections of environmental and scientific bodies. Industry pressure on scientists has at times been explicit. It isinsidious in its effect and therefore cuts acrossavailability and access to science as a public good. 


\section{O range Roughy Fisheries}

FIG 1 ORANGE ROUGHY STOCK DECLINES. THE DOTTED LINE REPRESENTS 30\% OF THE

UNFISHED BIOMASS, THE VOLUME CALCULATED TO PROVIDE THE MAXIMUM SUSTAINABLE YIELD. THIS IS THE LEGAL MINIMUM FOR TARGET FISH STOCKS, WHICH THE FISHERIES ACT 1996 (s.13)
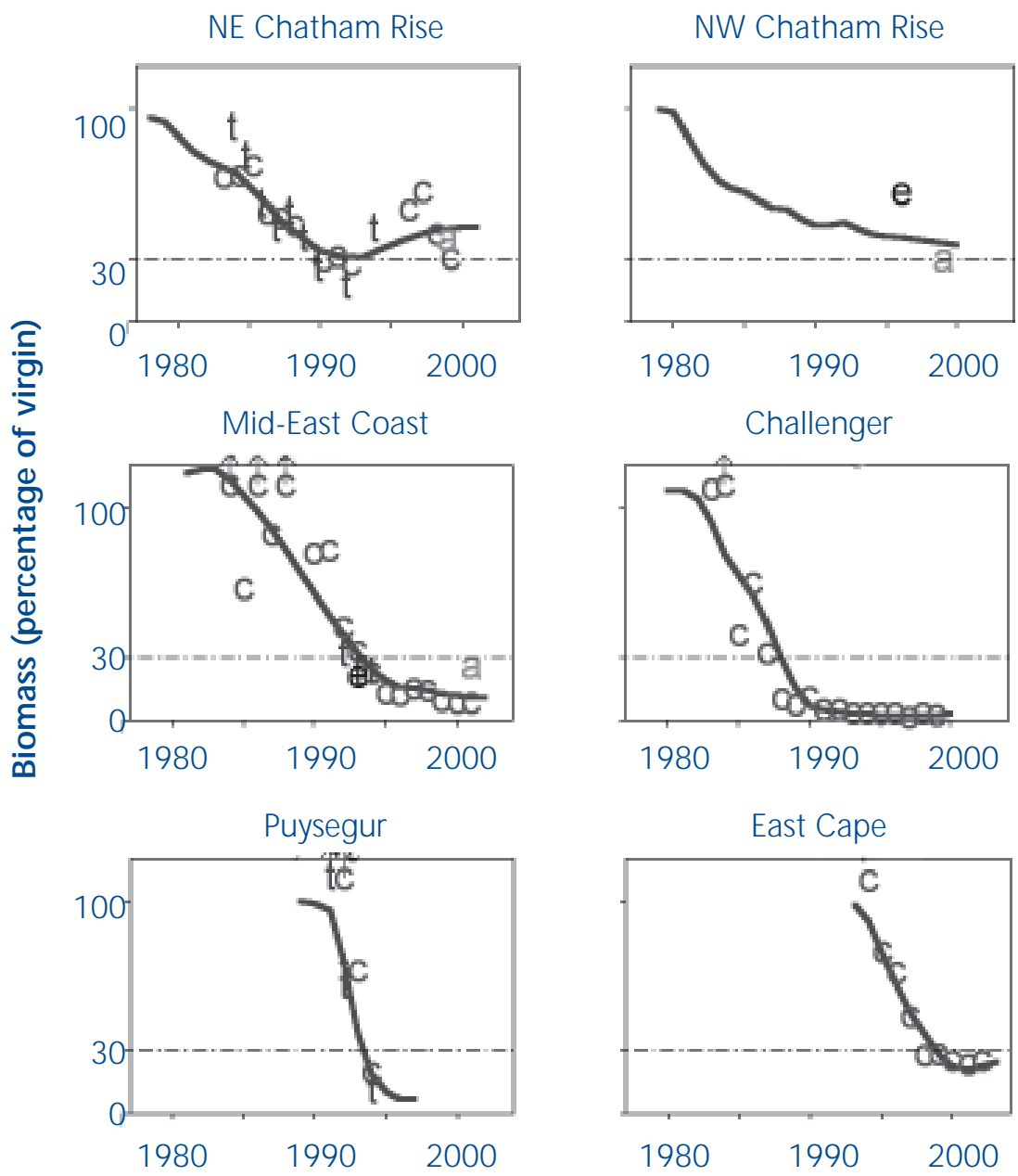

NW Chatham Rise

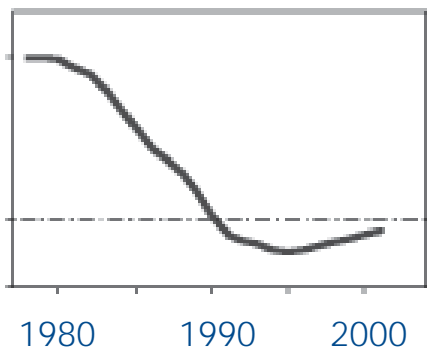

Challenger

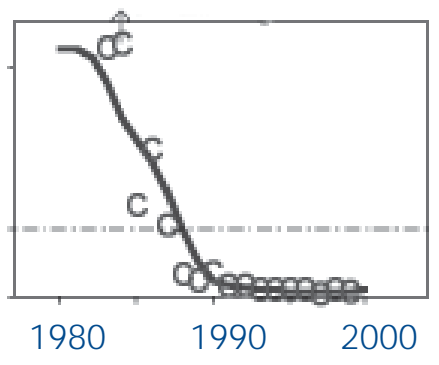

Cook Canyon
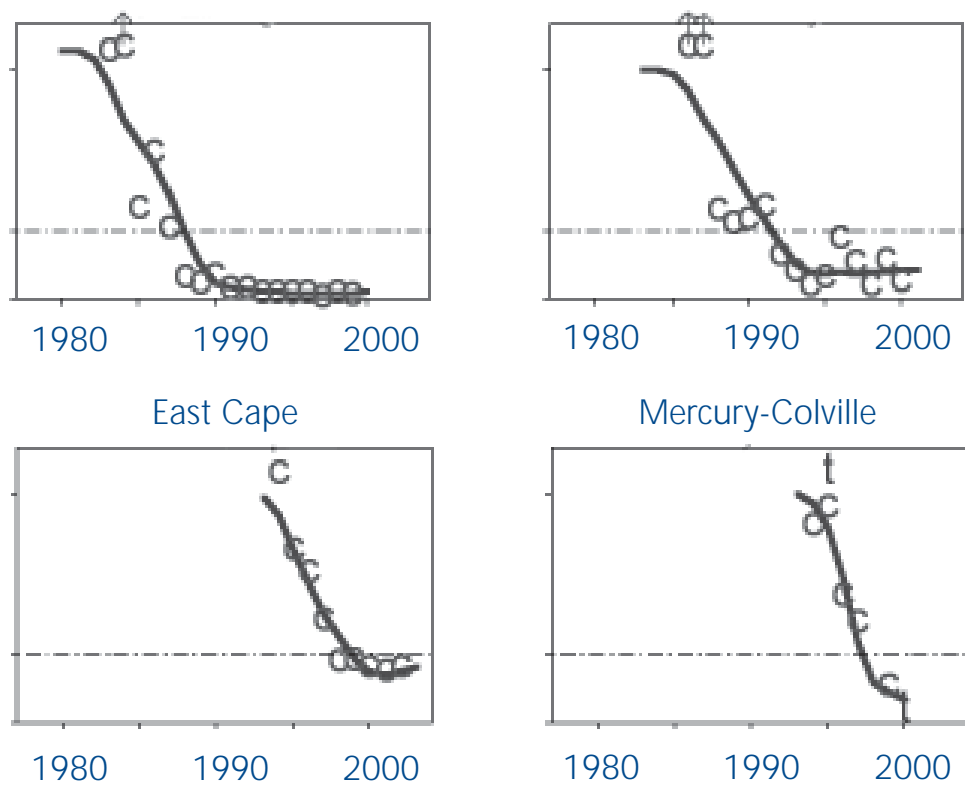

Note: letters on the graphs refer to the type of stock assessment: $c=$ catch per unit effort, $a=$ acoustic survey, $t=$ trawl survey, $e=$ egg survey Source: Malcolm Clark, National Institute of Water and Atmosphere (NIWA), New Zealand.

- Is there sufficient evidence to rule out the "hardlanding" (heavy stock depletion) option in future decisions on total allowable catch?

The fishing industry has preferred to take higher immediate catches and accept "hard landings", meaning that future allocations will be much reduced. The very rapid stock reduction illustrated in the orange roughy case suggests this choice was driven by discount rate factors and that it is unsustainable for deep-water fisheries. When the eventual catch cuts occurred, $M$ inisters were nevertheless given the blame!
- Why is there no environment assessment process nearly ten years after the passage of the Fisheries Act, which is quite specific on the requirement to avoid, remedy or mitigate any adverse effects of fishing on the aquatic environment (s.8), on the mandatory consideration of environmental principles (s.9) and the precautionary approach required (s.10)?

In the deep-sea environment there are unique requirements for any effective process of environmental assessment. The most obvious is the large input of resource for accurate monitoring of environmental damage and for stock assessment. 
Preparation for a Strategy for $M$ anaging the Environmental Effects of Fishing eventually began in 2001 but has languished. It may now, with a new Chief Executive at the helm, be revived.

A rapid response requirement is vital; that is, the TAC must be automatically reduced when signs of depletion are registered. "Second opinions" can follow, but the precautionary principleshould al ways apply.

- H ow should the resources begenerated for adequate management of ITQ $s$ or any other allocative mechanism?

The cost recovery system suffers the flaw of providing a potent mechanism for industry capture of fisheries management and research. Resource rentals have been eschewed since they were abandoned by a government under challenge from $M$ aori as to whether the government did indeed own the resource and hence have legitimacy in imposing a resource rental.

TheAuditor-G eneral in 1999 found that low priority was given in the budget process to funding for information and environmental science and management. The evidence in the original paper points to a familiar combination of spineless political management and bureaucratic surrender. The industry comes out repeatedly as the clear winner.

- How are non-market values to be reflected in fisheries management and how can the public be involved in the process of fisheries management?

Both the Resource M anagement Act and the Conservation Act provide examples of the way in which such values can be articulated in law. They also include specific mechanisms for engaging the public in conservation policy and resource management planning. An essential element is that all parties have equal and effective access to input and influence.

\section{Research findings}

In the Q ueenstown paper we also isolated three key questions:

a) D oes theory suggest a property rights regime alone can be relied on to protect fish stocks and the environment of the deep sea?

b) $\mathrm{H}$ as the $\mathrm{N}$ ew Zealand Q uota $\mathrm{M}$ anagement System been a success in terms of management of fish stocks and the deep-sea environment?

c) What wider lessons for deep-sea resource management can we learn?

O ur responseswerenegativeon both a) and b); thisopinion was based on dynamic economic harvesting theory and the evidence of the fish stocks and lack of environmental controls. As stated above, when a species is slow-growing high discount rates will provide a dominant incentive to extract the resource (and find a commercially better placement for the proceeds elsewhere).

Similarly, incentives to avoid damageto theenvironment are not provided by the Q uota M anagement System or ITQ S; instead, such effects continue to be externalised. The ecosystem values of non-target species will effectively be disregarded. Perhaps the central confusion stems from the fact that commercial interests have been able to interpret ITQ $\mathrm{s}$ as a grant of untrammeled property rights (and sometimes to threaten litigation on these grounds). This has reinforced the industry's instinct to resist any public benefit through more effective environmental controls.

Weconclude therefore that the $\mathrm{N}$ ew Zeal and experience brings out theway in which a property rightsmechanism can lead various stakeholders to lose sight of societal and other interests. Thiscomes about because thosenoncommercial rights are not codified in the quota system. The basic error is to leave industry with the illusion of unattenuated "ownership". Almost inevitably, the role of the public sector (as the principal agent for the interests of society and theenvironment) is then eclipsed. O ncethis happens, theadministrative principles behind a quota management system and enforcement of catch limits will, like the target fishery itself, collapse.

In future (and this was our answer to the third question), it will be crucial to configureany institutional framework so that industry pressure is not dominant. Groups that want to see higher fish stocks retained for non-extractive and ecosystem purposes should have an effective voice, and the resources to use it. Some jurisdictions use an independent board to set catch limits and controls - but accountability mechanisms then have to be put in place. In theN ew Zealand context an independent board could perform that role, with $M$ inisters required to report to Parliament on any proposed variation. 


\section{A design for the future}

Any resolution of these issues will need to recognize that wearenot in a static policy scenario, either in the national or international context. Resourcedepletion in theoceans is leading on to new initiatives. M ost recently, in $\mathrm{N} \mathrm{ew}$ Zealand, the whole process of developing an "O ceans Policy" wasinitiated - and later stalled. Ecosystem-based management in the high seas is under active discussion at the U nited $\mathrm{N}$ ations and el sewhere, as are controls on high seas fishing, particularly bottom trawling.

In all these situations, our public authorities need to assert the powers vested in them by statute and to provide for ecosystem-based management of fishing and other activities. They will need to levy resource rentals and recover management costs, and these decisions must be decoupled from undue industry influence. 0 nly in this way can research on, and management of, $\mathrm{New}$ Zealand fisheries display the same integrity as that operating in other areas of the public estate.

Rejigging incentives to reduce environmental damage is crucial. Public authorities must require that fishers, like their terrestrial counterparts, take steps to avoid, remedy or mitigate adverse effects of fishing. Such a rearrangement of the quota management system might of course be seen as some sort of economic sacrifice, or as "capitulation to the greenies". This has been a typical reaction in many similar situations, but it loses sight of the bigger picture and of the specific legal obligations that $\mathrm{N}$ ew Zealand has accepted under the UN Convention on the Law of the Sea. M oreover, economic efficiency would be enhanced by reform.

Under the UN Convention on the Law of the Sea (which is where the whole EEZ entitlement started) each nation state carries an absolute obligation "to preserve and protect the marine environment" (Art. 192) and to ensure that the management of marine resources meets other criteria endorsed by the international community. $\mathrm{N}$ ew Zealand has already come under intense criticism from the international community (at the 2004 United N ations Informal Consultation on $O$ ceans and the Law of the Sea) for the impacts of our bottom trawlers on the high sea. This attention is set to intensify.

It follows that a revamp of fisheries management would in essence represent the responsible exercise of the obligations accepted by $\mathrm{N}$ ew Zealand in this sector.
W ithout such reform, it is clear that we shall not live up to our own concerns for sustainable development, and for the equitable distribution of benefits to $\mathrm{N} \mathrm{ew}$ Zealand citizens, including future generations.

Cath Wallace is Senior Lecturer in the School of Government at VUW (as mentioned on p.2), with an international reputation for her policy work over many years on oceans, fisheries and Antarctic ecosystems, and for her contribution as a Council Member of the World Conservation Union (IUCN). Barry Weeber is Senior Researcher at Forest and Bird (Central O ffice) in Wellington and in 2003 he collaborated with Cath on the paper referred to in the opening paragraph, entitled "B etween the D evil and the D eep Blue Sea".

The exhaustive bibliography assembled for the authors' 2003 paper will be posted on the IPS website, and readers wishing to makee-mail contact with the authors can use:

Cath.Wallace@vuw.ac.nz

b.weeber@forestandbird.org.nz

Thekey reference for thestatistical material used in this article is;

Annala, J.H., et al., (2003) "Report from the fishery assessment plenary, M ay 2003: stock assessmentsand yield estimates" M inistry of Fisheries. (Unpublished report held in N IWA Library, Wellington) 